\title{
PENINGKATAN HASIL BELAJAR DRIBBLING SEPAKBOLA DENGAN PENGGUNAAN MEDIA AUDIO VISUAL
}

\author{
Muhamad Syamsul Taufik ${ }^{1)}$, Muhamad Guntur Gaos Sungkawa ${ }^{2)}$ \\ Pendidikan Jasmani,Keshatan dan Rekreasi Fakultas Keguruan dan Ilmu Pendidikan \\ Universitas Surya Kancana \\ email : ${ }_{2}^{1}$ Syamsul@unsur.ac.id
}

\begin{abstract}
ABSTRAK
Tujuan penelitian Action research ini adalah untuk meningkatkan hasil belajar dribbling pada mata pelajaran sepakbola melalui media audio visual untuk pendidikan jasmani. Selain itu, penelitian dilakukan untuk memperoleh informasi tentang, penerapan Media Audio Visual untuk siswa Kelas XI Sekolah Menengah Atas. Penelitian Action Research ini menggunakan pendekatan Kualitatif. Subjek dalam penelitian ini adalah siswa kelas XI SMA PGRI Ciawi Kabupaten Bogor. Penelitian ini dilakukan dengan enam belas kali pertemuan terdiri dari dua siklus, setiap siklus delapan kali pertemuan. Pada hasil test pembelajaran sebelumnya (pre test) memperoleh 36,6\% dari kriteria yang diharapkan. Sedangkan tingkat keefektifitasan Hasil belajar siswa pada siklus I nilai rata-rata kelas pembelajaran gerak dribbling adalah 74,7 dengan persentase ketuntasan 66,7\% dengan siswa yang lulus 20 Orang dan rata-rata kelas pada hasil belajar siswa pada siklus II adalah 80,7 dengan persentase kelulusan $83,3 \%$ dengan siswa yang lulus 25 artinya mengalami peningkatan sebesar 46,7\%. Berdasarkan hasil penelitian ini dapat disimpulkan bahwa : (1) dengan penerapan penggunaan media audio visual dalam pembelajaran dribbling meningkatkan hasil belajar siswa (2), para siswa lebih serius, dan lebih semangat proses pembelajaran.
\end{abstract}

Kata Kunci : hasil belajar. dribbling. media audio visual, siklus.

\section{ABSTRACT}

The purpose of this Action research research is to improve the learning outcomes of Dribbling in soccer subjects through audio visual media for physical education. In addition, research was conducted to obtain information about the application of audio visual media for Grade XI High School students. This Action Research study uses a Qualitative approach. The subjects in this study were students of class XI SMA PGRI Ciawi Bogor district. This research was conducted with sixteen meetings consisting of two cycles, each cycle of eight meetings. In the results of the previous learning test (pre-test) obtained 36.6\% of the expected criteria. While the level of effectiveness of student learning outcomes in the first cycle the average value of the dribbling motion learning class was 74.7 with a percentage of completeness $66.7 \%$ with students who passed 20 points and the average class on student learning outcomes in the second cycle was 80.7 with a graduation percentage of $83.3 \%$ with 25 students graduating. This means an increase of $46.7 \%$. Based on the results of this study it can be concluded that: (1) the application of the use of audio visual media in dribbling learning improves student learning outcomes (2), students are more serious, and more enthusiastic about the learning process.

Keywords: learning outcomes. dribbling. audio visual media, cycles

\footnotetext{
$凶$ Alamat korespondensi:

E-mail: Syamsul@unsur.ac.id

Info Artikel

Dikirim : $: 26$ Agustus 2019

Diterima $\quad: 21$ Oktober 2019

DOI $\quad:$ https://doi.org/10.33503/jp.jok.v3i1.540
}

(C) 2019 IKIP BUDI UTOMO MALANG 


\section{PENDAHULUAN}

Pendidikan adalah hal yang sangat penting bagi kehidupan manusia, karena pendidikan adalah suatu proses memanusiakan manusia. Maksudnya, menjadikan manusia yang lebih bermoral, berakal sehat, dan lain-lain. Saat ini, banyak orang yang berwujud manusia, tapi tidak menjalankan normanya sebagai manusia. Untuk itu, pendidikan adalah salah satu proses yang bisa dijadikan alternatif untuk pendidikan karakter, agar terwujudnya manusia yang bernorma. Dari banyak penelitian yang dilakukan dibidang pendidikan jasmani menunjukan bahwa kurikulum pendidikan jasmani tidak pada tepat dan memuaskan (Ljubojevi, Muratovi, \& Bubanja, 2016).

Berdasarkan pernyataan tersebut, dapat disimpulkan bahwa pendidikan adalah suatu usaha untuk mewujudkan aktivitas belajar dan mengembangkan setiap potensi yang ada dari peserta didik agar memiliki keterampilan untuk dirinya maupun untuk masyarakat. Pendidikan bersifat universal, bisa terbagi ke dalam beberapa aspek, salah satunya adalah pendidikan jasmani menurut (Burstiando \& Nurkholis, 2017) menyatakan bahwa dalam kegiatan belajar pembelajaran disekolah siswa dibekali bebagai macam hal dari mulai pembelajaran yang bersifat kognitif, afektif maupun psikomotor. Menurut (Widiastuti, 2014) keterampilan gerak adalah kemampuan untuk melakukan gerakan secara efisien serta perwujudan dari kualitas koordinasi dan kontrol atas bagian bagian tubuh yang terlibat dalam gerakan. Berdasarkan pernyataan tersebut dapat dikatakan bahwa pendidikan jasmani adalah suatu pendidikan yang terfokus pada gerak manusia (human movement) berupa aktivitas jasmani dan olahraga.

Pendidikan jasmani merupakan proses pendidikan melalui aktivitas jasmani yang mengembangkan aspek fisik, mental maupun emosional seseorang secara menyeluruh. Sepakbola juga memiliki gerakan yang lengkap, seperti gerakan kaki pada saat berlari menendang bola ke gawamg lawan.Dalam permainan sepakbola setiap pemain harus memiliki keterampilan teknik dasar yang baik dan dituntut kerjasama tim dalam bermain. (Serra-Olivares, Garcia-Lopez, \& Guncalves, 2019) " the ability to retain the ball possession and progress on the field to create goal-scoring opportunities seems to be dependent on the players' ability to create and use the available space. In contrast, youngest and less skilled players tend to 
be focused on the ball, leading to a high concentration of players around it. This higher focus on the ball may limit the players' ability to identify and use the available space in a functional way, which as a consequence affects the team behaviour".

Menurut (Sodikin \& Ahmad, 2010) bahwa sepak bola merupakan permainan yang dilakukan oleh dua regu/tim. Setiap tim terdiri atas 11 pemainan sepakbola membutuhkan kerja sama tim yang kompak. Disamping itu, dengan variasi dan kombinasi dengan teknik-teknik dasar juga diperlukan dalam permanian ini. Dribbling merupakan kemampuan menggiring bola dari satu tempat ketempat lain dengan tetap menguasai bola yang berguna untuk menghindari hadangan lawan dan untuk mengatur tempo permainan. Tanpa kemampuan dribbling yang baik maka seorang pemain akan terlihat sebagai seorang pemain yang baru pandai bermain sepak bola.

Dribbling dipengaruhi oleh beberapa faktor seperti pengalaman bermain yang dimiliki, semakin lama seseorang berlatih tentunya kemampuannya juga akan semakin baik. Perkenaan kaki terhadap bola juga menentukan keberhasilan dribbling karena perkenaan kaki yang benar dengan bola akan memudahkan pesepakbola bergerak dengan cepat. Setelah itu pandangan yang tidak hanya melihat ke bola tapi kesegala arah juga akan membuat pesepakbola mampu melakukan dribbling semakin bermanfaat dengan bergerak menjauhi lawan dan dribbling juga dipengaruhi oleh beberapa faktor kondisi fisik seperti keseimbangan dan kecepatan serta aspek psikologi seperti percaya diri dan motivasi.

Berdasarkan Obeservasi lapangan yang peneliti lakukan di SMAN PGRI Ciawi diketahui bahwa nilai KKM (kriteria Ketuntasan minimum) untuk mata pelajaran pendidikan jasmani adalah 75. Kenyatan menunjukan bahwa dari 30 orang siswa kelas XI yang mencapai ketuntasan minimum (KKM) untuk materi Sepakbola dribbling adalah 11 orang dan yang tidak mencapai minimum (KKM) sekitar 19 orang. Rendahnya hasil belajar dribbling pada siswa di SMAN PGRI Ciawi ini dikarenakan pada dasarnya metode pembelajaran yang hanya berpusat pada guru saja, dalam hal ini guru hanya memberi contoh gerakan kepada siswanya dan siswa hanya mengikuti intruksi yang diberikan oleh gurunya, hal 
ini dikarenakan guru salah dalam memilih metode pembelajaran yang tepat, yang sepenuhnya guru mengambil peran dalam pembelajaran dan membuat siswa malas, jenuh dan bosan dalam mengikuti pembelajaran dribbling (Sepakbola)

Apabila dribbling dipelajari dengan metode yang cocok, dribbling akan memberikan hasil yang baik sehingga dalam melakukan serangan permainan Sepakbola, angka atau nilai yang dihasilkan oleh dribbling akan sangat tinggi sekali. Namun dalam beberapa kasus di pembelajaran dribbling disekolah masih terdapat kendala kurang variatifnya metode pembelajaran yang diterapkan para guru dalam memberikan pembelajaran tentang keterampilan dribbling.

Bila guru pendidikan jasmani menggunakan metode yang tepat dalam proses pembelajarannya maka akan membuat siswa lebih perhatian terhadap pembelajaran tersebut dan jika siswa mulai memberikan perhatian dalam pembelajaran tersebut maka siswa akan lebih memahami dan mudah mengerti tentang pembelajaran yang telah diberikan oleh gurunya tersebut. Tapi dalam hal ini bukan hanya metode pembelajaran saja yang diperlukan tapi juga media sebagai alat penyampaian informasi kepada siswa agar lebih mudah memahami materi yang disampaikan oleh para guru.

Media adalah segala sesuatu yang digunakan untuk pengiriman pesan yang digunakan untuk memberikan rangsangan pada pikiran, perasaan, perhatian serta minat menurut Sadiman (Firmansyah, Hariyanto, \& Kurniawan, 2019). Adapun Rossie dan Breidle dalam (Sanjaya, 2006) mengatakan media pembelajaran adalah seluruh alat dan bahan yang didapat dipakai untuk mencapai tujuan pendidikan seperti radio,televisi, buku, koran, majalah dan sebagainya. (Zainal, 2015) menyatakan media pembelajaran adalah segala sesuatu yang dapat digunakan untuk menyalurkan pesan dan merangsang terjadinya proses pembelajaran pada pembelajaran siswa.

Beberapa penelitian sesuai dengan rujukan awal pendukung dari penelitian yang membahas tentang belajar dribbling dengan media audio visual ini untuk pembelajaran sepakbola terdapat pengembangan model pembelajaran passing pemain sepakbola (Ngolo \& Abdul, 2018), peningkatan hasil belajar passing sepak bola melalui permainan pemburu binatang (Setiawan \& Akhiruyanto, 2015), peningkatan pembelajaran sepak bola melalui modifikasi permainan 
sepak bola (Dora) (Nururi \& Sulaiman, 2015), pengembangan model pembelajaran sepakbola dengan permainan "Balangka" (Andrian \& Yuwono, 2015) Sedangkan penelitian yang berkaitan dengan media audio visual yaitu pembelajaran lay up shoot menggunakan media audio visual basic lay up shoot (Febryanto, 2015). Jenis media audio visiual yang sudah digunakan diantaranya (Istiawan \& Kusdianto, 2018) menggunakan android, (Yuniarto, Supriyadi, \& Sudjana, 2018) berbasis mobile learning, (Firmansyah \& Hariyanto, 2019) menggunakan $Q R$ Code.

Jika Selama Ini para guru pendidikan jasmani hanya menyajikan pembelajaran Sepakbola dribbling lewat informasi contoh atau peragaan, maka kali ini guru pendidikan jasmani akan menyajikan pembelajaran dengan menggunakan media audio visual yang ditampilkan melalui komputer atau laptop dan ditayangkan kepada siswa melalui sebuah alat infokus. Dengan memanfaatkan media audio visual ini diharapkan para siswa dapat mengerti dan melakukan gerakan dribbling dengan baik dan benar, serta meningkat minat dan hasil belajar siswa.

Untuk mencapai tujuan pembelajaran dribbling disekolah tersebut, guru pendidikan jasmani harus dapat merancang dan melaksanakan pembelajaran pendidikan jasmani sesuai dengan tahap-tahap perkembangan dan karakteristik anak didik, terutama di Sekolah serta menggunakan media yaitu audio visual merupakan salah satu upaya yang dapat dilakukan guru pendidikan jasmani agar pembelajaran dapat mencerminkan proses belajar dan mendapatkan hasil yang baik dengan bantuan alat tersebut dan tercapai nya keberhasila siswa melakukan pembelajarn dribbling sepakbola.

Berdasarkan pandangan diatas pembelajaran dribbling menggunakan audio visual dapat dengan berjalan efektif dan meningkatkan kualitas pembelajaran penjas disekolah.sehinga peneliti tertarik pengambil penelitian yaitu peningkatan hasil belajar dribbling Sepakbola dengan penggunaan media audio visual.

\section{METODE}

Metode Penelitian yang digunakan adalah metode penelitian tindakan atau (actionresearch) (Arikunto, 2016) menjelaskan Penelitian tindakan adalah 
penelitian yang dilakukan oleh guru dengan tujuan memperbaiki mutu pembelajarfan dikelasnya. Penelitian tindakan berfokus pada proses belajar mengajar yang terjadi dikelas, Penelitian tindakan (Action Research) ini menggunakan desain penelitian Model Kemmis dan Mc.Taggart yang berupa siklus atau putaran kegiatan yang meliputi tahapan sebagai berikut:

1) Perencanaan (Planning) Perencanaan yang matang perlu dilakukan setelah kita mengetahui masalah dalam pembelajaran kita. 2) Tindakan (Action) Perencanaan harus diwujudkan dengan adanya (Action) dari guru berupa solusi tindakan sebelumnya. 3) Pengamatan (Observing) Selanjutnya diadakan pengamatan (Observating) yang teliti terhadap proses pelaksanaannya. 4) Refleksi (Reflecting) Setelah diamati, Barulah guru dapat melakukan refleksi (refecting) dan dapat menyimpulkan apa yang telat terjadi dalam kelasnya.

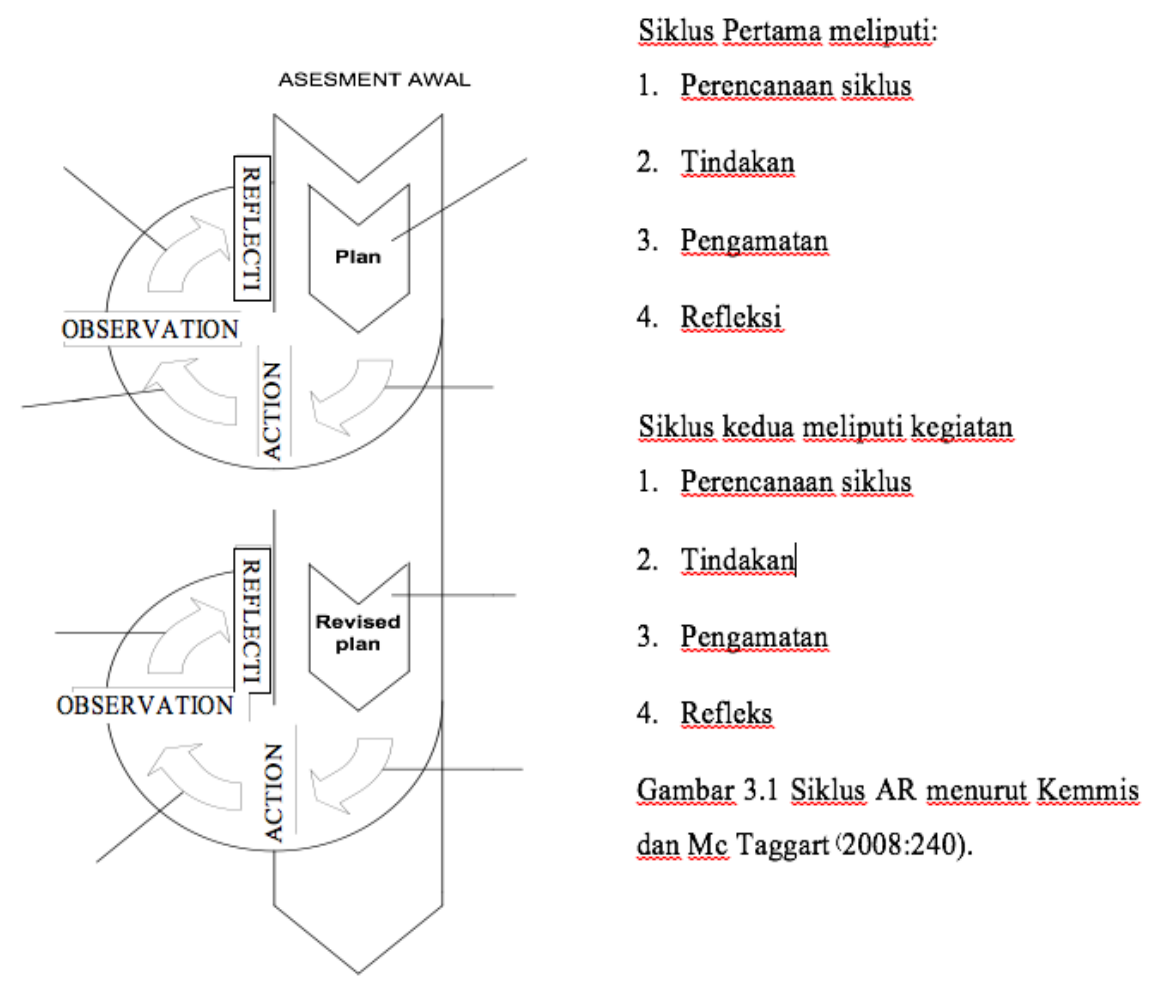

Gambar 1. Desain Penelitian Tindakan Model Kemmis dan Mc.Taggart

1) Perencanaan (Planning) Perencanaan dalam pembelajaran menyiapkan audio visual video dribbling sepakbola top sepakbola 2) Tindakan (Action) kemudia guru menyiapkan alat audio visual serta memberikan hasil video temuan dribbling sepakbola 3) Pengamatan (Observing) Selanjutnya diadakan pengamatan (Observating) oleh siswa terkait video dribbling tersebut agar siswa tujuan nya 
bias melakukan Gerakan dribbling dengan sempurna. 4) Refleksi (Reflecting) Setelah diamati, Barulah guru dapat melakukan refleksi (refecting) kepada siswa dan siswa bias melakukannya dan dapat menyimpulkan apa yang telat terjadi dalam kelasnya serta mengoreksi yang dilakukan siswanya.

\section{HASIL PENELITIAN}

Berdasarkan refleksi dari analisa data yang terkumpul maka hasil penelitian tindakan siklus I pada tes dribbling siswa kelas XI SMAN 1 PGRI Ciawi menunjukan bahwa hasil belajar dari dribbling masih sangat rendah. Hal tersebut dapat dilihat pada data hasil belajar gerakan dribbling para siswa, data hasil observasi kelas terhadap guru, dan data hasil observasi terhadap siswa sebagai berikut ini:

1). Siklus I

Tabel 1. hasil Ketuntasan Hasil Belajar Dribbling Siklus I

\begin{tabular}{ll}
\hline Ketuntasan & Persen $(\%)$ \\
\hline Tuntas & $66,7 \%$ \\
\hline Tidak Tuntas & $33,3 \%$ \\
\hline Jumlah & $100 \%$
\end{tabular}

Dengan demikian dengan temuan diatas, hasil belajar dari dribbling masih sangat rendah, hal ini disebabkan karena, metode pembelajaran yang menggunakan media audio visual yang diterapkan masih bersifat satu arah dari guru melalui siswa saja dan tidak dijelaskan secara baik oleh guru. Pelaksanaan pembelajaran selama delapan pertemuan belum sepenuhnya sesuai dengan RPP yang telah dibuat oleh guru, sikap Guru dalam memberikan pembelajaran mulai dari pemanasan, inti dan pendinginan masih belum sepenuhnya mengacu pada RPP.

Data kualitatif pada siklus I menunjukan dari kelima aspek gerakan ada dua gerakan yang sulit atau belum sempurna dilakukan oleh siswa yaitu perkenaan kaki dengan bola dan sentuhan kaki terlalu jauh jaraknya. Berdasarkan hasil penilaian proses pembelajaran melalui penerapan penggunaan media audio visual pada hasil belajar dribbling yang dilakukan kolaborator pada observasi penilaian 
kelas terhadap guru di siklus I diperoleh pada pertemuan ke-1 dan ke-2 terdapat skor 2,8, pada pertemuan ke-3 dan ke-4 terdapat skor 2,9, pada pertemuan ke-5 dan ke-6 terdapat skor 3,0 dan meningkat pada pertemuan ke-7 dan ke-8 terdapat skor 3,1, sehingga pelaksanaan berlangsung dengan cukup baik

Sedangkan untuk penilaian dari kolaborator untuk observasi kelas terhadap siswa selama proses pembelajaran berlangsung pada siklus I maka, diperoleh skor rata-rata pada pertemuan 1 dan 2 terdapat skor 2,3, dilanjut dengan pertemuan ke3 dan ke-4 terdapat skor-2,5, pertemuan ke-5 dan ke-6 terdapat skor 2,7, dan pertemuan ke-7 dan ke-8 mendapat skor 2,9, sehingga dapat diartikan siswa dalam melaksanakan pembelajaran ada peningkatan walaupun baru sedikit sehingga dapat diartikan siswa dalam melaksanakan pembelajaran ada peningkatan walaupun baru sedikit.

Peneliti dan kolaborator menyimpulkan bahwa hasil belajar siswa dari tes hasil belajar siklus I masih rendah. Pada siklus ini ketuntasan hasil belajar siswa belum memenuhi kriteria ketuntasan ketuntasan minimum dengan persentase ketuntasan 66,7\% . jadi pada siklus yang I ini masih belum mencapai persentase ketuntasan klasikal yang seharusnya $80 \%$.

\section{2). Siklus II}

Pada siklus II ini pemahaman siswa dalam hasil belajar Dribbling sudah semakin baik dan koordinasi gerak dasar secara individu pun meningkat. Hal tersebut dapat dilihat pada data hasil belajar gerakan Dribbling para siswa, data hasil observasi terhadap guru yaitu, dan data hasil observasi terhadap siswa sebagai berikut ini :

Tabel 2. Hasil Ketuntasan Hasil Belajar Dribbling Siklus II

\begin{tabular}{ll}
\hline Ketuntasan & Persen (\%) \\
\hline Tuntas & $88,3 \%$ \\
\hline Tidak Tuntas & $16,7 \%$ \\
\hline Jumlah & $100 \%$
\end{tabular}

Hasil catatan lapangan pada siklus II menunjukkan bahwa dalam proses pembelajaran para siswa sudah mulai meningkat dibanding siklus I. Begitupun 
pada kelima aspek gerakan semuanya mengalami peningkatan yang signifikan, kemudian 5 orang yang belum mencapai ketuntasan belajar akan dilanjutkan oleh guru penjas dengan diberikan ujian remedial.

Hasil penilaian observasi yang dilakukan dikelas terhadap guru yang di lakukan kolaborator pada siklus II yang diperoleh dari pertemuan pertama dan ke2 mendapat skor rata-rata 3,1, lanjut ke pertemuan ke-3 dan ke-4 terdapat skor rata-rata 3,3, untuk pertemuan ke-5 dan ke-6 skor rata-rata yang diperoleh 3,5, dan untuk pertemuan ke-7 dan ke-8 skor rata-rata 3,9 sehingga pelaksanaan berlangsung dengan sangat baik. Kekurangan kekurangan yang terjadi pada siklus yang pertama sudah diperbaiki dalam siklus kedua ini berdasarkan koreksi kolaborator.

Berdasarkan penilaian kolaborator terhadap observasi kelas untuk siswa di siklus II ini dalam proses pembelajaran yang diberikan Guru dalam penerapan dengan menggunakan media audio visual proses pembelajaran berlangsung maka dapat diperoleh skor rata-rata pada pertemuan pertama dan ke-2 terdapat skor rata 2,5, pertemuan ke-3 dan ke-4 terdapat skor rata-rata 2,7, untuk pertemuan ke-5 dan ke-6 terdapat skor rata-rata 2,9, dan dipertemuan ke-7 dan ke-8 meningkat skor rata-rata yang diperoleh 3,1, sehingga dapat diartikan siswa dalam melaksanakan pembelajaran mengalami peningkatan kondisi belajar.

Berdasarkan hal tersebut peneliti dengan kolaborator membandingkan hasil belajar dribbling dengan penerapan penggunaaan media audio visual pada saat pembelajaran sepakbola di siklus I dan II. Jadi menurut (Burstiando \& Nurkholis, 2017) menyatakan bahwa dalam kegiatan belajar pembelajaran disekolah siswa dibekali bebagai macam hal dari mulai pembelajaran yang bersifat kognitif, afektif maupun psikomotor oleh karena itu dari dua penjelasan proses kegiatan setiap siklus yaitu siklus I dan II.

Dapat disimpulkan berdasarkan teori dan pandangan diatas bahwa pembelajaran yang efektif gabungan antara kognitif dan psikomotor jadi kemampuan melihat melalui media audio visual bisa diterapkan melakukan kemampuan dribbling dilihat dari ketuntasan hasil belajar siswa pada siklus II ini sudah memenuhi kriteria yang ketutasannya minimum dengan persentase 
ketuntasan $83,3 \%$. jadi pada siklus II ini sudah mencapai persentase ketuntasan klasikal $80 \%$.

\section{SIMPULAN}

Berdasarkan hasil temuan pada setiap tahapan penelitian dan hasil pembahasan yang dijelaskan secara detail diatas telah didapatkan oleh peneliti dan dipaparkan, secara umum dapat disimpulkan bahwa adanya peningkatan pada siklus II ini sudah mencapai persentase ketuntasan klasikal $80 \%$. Sehingga dapat dijabarkan adanya peningkatan hasil belajar siswa dengan melalui pembelajaran pendidikan jasmani dribbling sepakbola dengan metode pembelajaran menggunakan media audio visual bagi siswa kelas XI SMA PGRI Ciawi Kabupaten Bogor serta pembelajaran berjalan secara efektif dan efesien.

\section{DAFTAR PUSTAKA}

Andrian, B. B., \& Yuwono, C. (2015). Pengembangan Model Pembelajaran Sepakbola dengan Permainan "Balangka." Active - Journal of Physical Education, Sport, Health and Recreation, 4(10), 2106-2111.

Arikunto, S. (2016). Penelitian Tindakan kelas. Jakarta: PT Bumi Aksara.

Burstiando, R., \& Nurkholis, M. (2017). Permainan Invasi dan Permainan Netting untuk Meningkatkan Keterampilan Gerak Dasar Fundamental Siswa SD Negeri Se Kecamatan Mojoroto Kota Kediri. Sportif: Jurnal Penelitian Dan Pembelajaran, 3(2), 167-177.

Febryanto, F. N. (2015). Pembelajaran Lay Up Shoot Menggunakan Media Audio

Visual Basic Lay Up Shoot Untuk Meningkatkan Hasilbelajar Lay Up Shoot Pada Siswa Kelas VIIIA SMP Kanisius Pati Tahun 2013/2014. Journal of Physical Education, Sport, Health and Recreations, 4(1), 1509-1521.

Firmansyah, G., \& Hariyanto, D. (2019). QR Code Based Teaching Materials for Organizational Classes and Game Systems. Journal of Physical Education, Health and Sport, 6(1), 6-10.

Firmansyah, G., Hariyanto, D., \& Kurniawan, R. (2019). Pengaruh Bahan Ajar Berbasis Qr Code Terhadap Motivasi Belajar Dan Keterampilan Dasar Bermain Tenis Meja. In Prosiding Seminar Nasional IPTEK Olahraga (pp. 
29-31).

Istiawan, N., \& Kusdianto, H. (2018). Pengaruh Bahan Ajar Myologi Berbasis

Android Untuk Meningkatkan Hasil Belajar Mahasiswa Pjkr Pada Mata

Kuliah Anatomi. Jp.jok (Jurnal Pendidikan. Jasmani, Olahraga Dan Kesehatan), 2(1), 13-19.

Ljubojevi, M., Muratovi, A., \& Bubanja, M. (2016). Effects of Various Physical Education Curriculum on Motor Skills in Students of Final Grades in Primary School. Sport Mont, 14, 25-28.

Ngolo, H., \& Abdul, M. N. (2018). Pengembangan Model Pembelajaran Passing Permainan Sepak Bola Di SMP Negeri 7 Wasilei Halmahera Timur. Jp.jok (Jurnal Pendidikan. Jasmani, Olahraga Dan Kesehatan), 2(1), 30-41.

Nururi, A. N., \& Sulaiman, S. (2015). Permainan Sepak Bola (Dora) Dalam Pembelajaran Penjasorkes Kelas VI SD Negeri Palebon 02 Kec. Pedurungan Kota Semarang Tahun 2013. Active - Journal of Physical Education, Sport, Health and Recreation, 4(7), 1957-1962.

Sanjaya, W. (2006). Strategi Pembelajaran. Jakarta: Penerbit Kencana Prenada Group.

Serra-Olivares, J., Garcia-Lopez, L. M., \& Guncalves, B. (2019). Effects of the players' level and age group category on positional tactical behaviour during 7- and 8-a-side football youth games. Journal International Journal of Performance Analysis in Sport, 19(2), 236-247.

Setiawan, A., \& Akhiruyanto, A. (2015). Peningkatan Hasil Belajar Passing Sepak Bola Melalui Permainan Pemburu Binatang. Active - Journal of Physical Education, Sport, Health and Recreation, 4(10), 2100-2105.

Sodikin, \& Ahmad. (2010). Pendidikan Jasmani Olahraga dan Kesehatan. Jakarta: Pusat Perbukuan Kementerian Pendidikan Nasional.

Widiastuti. (2014). Belajar Keterampilan Gerak. Jakarta: FIK Universitas Negeri Jakarta.

Yuniarto, A., Supriyadi, \& Sudjana, I. N. (2018). Pengembangan Media Pembelajaran Berbasis Mobile Learning Teknik Dasar Dan Peraturan Permainan Futsal. Jp.jok (Jurnal Pendidikan. Jasmani, Olahraga Dan Kesehatan), 2(1), 51-62. 
Zainal, A. (2015). Model-model, Media dan strategi Pembelajaran Konstektual. Jakarta: Yrama Widya. 